IdeAs

Idées d'Amériques

$6 \mid 2015$

Migrer dans les Amériques

\title{
Migrar nas Américas
}

\section{Françoise Lestage e Paul Schor}

\section{(2) OpenEdition}

\section{Journals}

Edição electrónica

URL: https://journals.openedition.org/ideas/4728

DOI: 10.4000/ideas.4728

ISSN: 1950-5701

Este artigo é uma tradução de:

Migrer dans les Amériques - URL : https://journals.openedition.org/ideas/1038 [

Outra(s) tradução(ões) deste artigo:

Migrating in the Americas - URL : https://journals.openedition.org/ideas/3084 [en]

Migrar en las Américas - URL : https://journals.openedition.org/ideas/3091 [es]

\section{Editora}

Institut des Amériques

\section{Refêrencia eletrónica}

Françoise Lestage e Paul Schor, «Migrar nas Américas», IdeAs [Online], 6 | 2015, posto online no dia 13 dezembro 2018, consultado o 19 outubro 2022. URL: http://journals.openedition.org/ideas/4728 ; DOI: https://doi.org/10.4000/ideas.4728

Este documento foi criado de forma automática no dia 19 outubro 2022.

\section{(c) () $\odot$}

Creative Commons - Atribuição-NãoComercial-SemDerivações 4.0 Internacional - CC BY-NC-ND 4.0 https://creativecommons.org/licenses/by-nc-nd/4.0/ 


\title{
Migrar nas Américas
}

\author{
Françoise Lestage e Paul Schor
}

Dedicado à migração nas Américas, este dossiê é dedicado à memória de Aristides Zolberg (1931-2013), cujo trabalho de desconstrução do mito dos EUA, terra dos migrantes $^{1}$ foi uma contribuição importante para o estudo das migrações e da construção nacional. Aristides Zolberg participou da conferência "A migração como legado" em junho de 2012, em Paris, onde vários textos incluídos neste número haviam sido discutidos ${ }^{2}$.

Se a migração é um fenômeno global, as Américas têm uma relação especial com ela, uma vez que a palavra "migração" é contemporânea das primeiras mobilidades transatlânticas após a "descoberta" da América no final do século XV. Desde então, as Américas - cuja atribuição de identidade de "Novo Mundo" já remete a uma temporalidade tecida por experiências de migração - conheceram várias ondas migratórias, transoceânicas e intra-americanas, que fizeram deste continente um ponto de encontro, de instalação, de confronto, mas também de troca de populações de diferentes partes do mundo. A nível continental, o que chama a atenção é "a longa duração" do fenômeno migratório, para não dizer seu caráter constitutivo. A América e sua população, em grande parte, receberam, de alguma forma, o "legado da migração."

Para evocar um tema tão central, os autores aqui reunidos mobilizaram métodos e recursos de várias disciplinas, história, geografia, antropologia, sociologia, usando diferentes escalas e períodos de tempo, a fim de iluminar, não uma imagem abrangente da migração nas Américas, o que seria impossível, mas o fato de que as migrações atuais e passadas afetam as experiências das populações migrantes e de seus descendentes e, mais amplamente, das sociedades nacionais e de acolhimento. Os estudos de migração, particularmente nas Américas, foram profundamente renovados desde suas origens e às vezes é difícil dar coerência a este fenômeno que hoje envolve múltiplas facetas. No entanto, é a ambição desse dossiê. A diversidade desejada das contribuições permite dar conta da diversidade de memórias, de experiências e de circulações, mas também foi possível juntar pesquisas que compartilham uma abordagem centrada na pessoa, no indivíduo e na experiência humana, direta ou indireta da migração. Através das correspondências, dos arquivos, das investigações de pesquisa, das figuras e dos 
motivos, emergem figuras de migrantes em movimento que, por seus deslocamentos, suas trilhas e suas conexões, dão a sua especificidade para o continente americano.

Fundadora das Américas, a migração contribui também para um sistema global, e a transição de uma escala para outra permite inserir os diferentes casos de migração no passado e no presente da globalização. Quer se trate de trabalhadores pobres, de migrantes qualificados, de ativistas ou de empresários, e quer se trate de caminhos bem definidos ou de práticas de circulação complexas entre regiões e países, os movimentos de migrantes relacionam os países e as diferentes áreas, cada vez mais interligadas. Nessa ótica, os artigos deste número - que em sua maioria se interessam pelos casos nacionais - permitem ver que os padrões de migração desenham a geografia do continente. E todos são afetados, incluindo aqueles que não migram.

Apesar da diversidade dos assuntos, os autores entretecem uma rede através de temas comuns. 0 primeiro deles é a memória viva da migração, a continuidade da experiência vivida, muito além do tempo de migração stricto sensu, nomeadamente por meio do estudo das correspondências, um material que conheceu recentemente um renascimento historiográfico. Os diferentes usos da correspondência dos migrantes e viajantes permitem ver como são feitas e desfeitas, ao longo do tempo, as redes transnacionais. Assim, o estudo de Aubert examina como, através da escrita e da fotografia, missionários episcopais produziram uma imagem literária e visual de suas "terras" do sul do continente, do Brasil ao Chile, num duplo movimento de exotização e de integração do projeto imperial estadunidense. Da Orden estuda as cartas de famílias migrantes sicilianas, na Argentina, por várias gerações (1910-1980). Nos dois casos, a correspondência permite reconstruir a temporalidade das experiências de migração. No que diz respeito ao artigo de Da Orden, vemos como a correspondência tem várias funções e torna-se, para o historiador, uma base para o estudo das relações de poder dentro das famílias, com reconfigurações das relações familiares no contexto da migração. Por sua vez, Venkovits analisa como a correspondência e os relatos de viajantes húngaros foram incentivados e orientados pelo governo de Porfirio Díaz para valorizá-los e seduzir os potenciais migrantes europeus para o México, em detrimento dos Estados Unidos.

A memória da migração, que ela seja parte de um plano político ou que se elabore como uma estratégia familiar estendida aos parentes, é expressa não só pelos escritos, mas também por uma patrimonialização através de objetos, primeiro transmitidos no seio familiar, em seguida reunidos em museus, como Daniel o demostra no caso dos descendentes de imigrantes finlandeses, judeus e alemães nos Estados Unidos. Dando aos objetos e arquivos familiares um lugar em museus étnicos, fazem deles uma instituição para o grupo e assim integram simbolicamente as comunidades no país de acolhimento. Esta etnia simbólica, produzida por gerações subsequentes, também inscreve a migração numa longa temporalidade, de várias gerações, onde a história e a memória estão interligadas.

Vemos que, quando se trata de migração, as idas e vindas entre os espaços e tempos são múltiplas e complexas. Isto é evidente quando se apreende a longa história de migração, mas este vaivém também é percpetível nos casos mais contemporâneos observados neste dossié. Ao analisar o comportamento dos migrantes enlutados em Quebec em 2010, Rachedi et al. fazem a constatação de uma ampla gama de comportamentos que vão do desejo de replicar os mesmos ritos funerários dos 
antepassados até a alteração ou a invenção de ritos inéditos que permitem aos imigrantes e a seus descendentes projetar-se para o futuro, na sociedade em que vivem.

o segundo tema é o da experiência da migração, que é, como já dissemos, uma perspectiva recente no trabalho sobre a migração. Vários autores consideram essa questão a partir da perspectiva do reconhecimento social, os migrantes desejando ter direitos e um estatuto de acordo com a sua participação econômica e política na sociedade de acolhimento. Schaffhauser centra-se na mobilização dos trabalhadores agrícolas mexicanos de 40 a 60 anos, os braceros, que na década de 2000 começaram a reivindicar uma pensão pela qual pagaram, mas que nunca recebram; Luconi compara a participação política dos imigrantes italianos na Argentina e a desta mesma comunidade italiana nos Estados Unidos, na primeira metade do século XX.

As conclusões dos dois autores diferem. Schaffhauser apresenta a recente experiência política dos braceros aposentados como uma contribuição democrática para a sociedade mexicana contemporânea; para este autor, as demandas dos braceros, que se mobilizam, com muito empenho, para que seus direitos sejam reconhecidos, "reinstitucionalizam" as instituições mexicanas, forçando-as a agir para cumprir a função de serviço público, o que está longe de ser o caso, atualmente, no México. Para Luconi, dependendo do lugar em que os migrantes italianos se estabeleceram, que seja nos Estados Unidos, já dominados pelos protestantes do norte da Europa, ou que seja na Argentina, onde a sociedade nacional ainda estava sendo construída, eles foram aceitos mais ou menos tarde na área política e puderam desempenhar um papel mais ou menos ativo. $\mathrm{Na}$ Argentina, a eleição do primeiro presidente de origem italiana, em 1890, marcou sem dúvida este reconhecimento, que ocorreu bem mais tarde nos Estados Unidos.

Projeto altamente político, a migração voluntária dos negros norte-americanos para o Haiti, antes da abolição da escravatura, mostra como aqueles que partem (e às vezes voltam), bem como aqueles que pensam em sair mas acabam permanecendo, estão envolvidos em construções políticas nacionais complexas, nestes casos as do Haiti e dos Estados Unidos. Bourhis-Mariotti dá um enfoque sobre este aspecto pouco conhecido da história do abolicionismo, onde a migração como projeto ou como uma realidade, molda indivíduos políticos, num sentido oposto às tendências vigentes nos Estados Unidos nos últimos anos da escravidão. A migração voluntária, para os descendentes de escravos, diferentemente dos projetos de emigração dos que foram alforriados por abolicionistas brancos, aparece como uma afirmação de liberdade e uma crítica ativa do racismo do regime político americano.

Cohen move o foco no íntimo, mostrando, a partir de uma observação participante, como os trabalhadores mexicanos sem documentos de um restaurante de Chicago mantiveram simultaneamente relações amorosas e familiares, cujo estatuto é diferente, nos dois lados da fronteira. Aqui, a fronteira estrutura relações amorosas marcadas pela desigualdade de gênero, mas também, em Chicago, por uma diversidade étnica e social (as namoradas não pertencem ao grupo e são mais educadas) que, segundo o que dizem os homens, seriam sem consequência. As relações assimétricas entre as mulheres americanas e os homens migrantes complicam as hierarquias de status e poder entre os migrantes e não migrantes, e vemos como a situação dos migrantes pode reordenar as modalidades mais pessoais.

Um terceiro tema da matéria é de medir como o movimento de pessoas entre os dois espaços, seja nas Américas (Morales, Baby-Collin), entre as Américas e a Europa (Gérard et Grediaga e Miret e Córdoba) ou entre a Ásia e as Américas (Essses, Medianu e Sutter), 
em estudos que partem de diversos objetos, tais como a mobilidade dos estudantes engenheiros mexicanos ou a relação do espaço vivido pelos colombianos de Barcelona.

Para Gerard e Grediaga que estudam os programas de formação de engenheiros mexicanos durante a segunda metade do século XX e que questionam a relação entre a mobilidade e a circulação do conhecimento num mundo globalizado e hierarquizado, as mobilidades têm efeitos paradoxais: eles acham que a construção da "cadeia do conhecimento", ou seja, a cooperação privilegiada entre instituições mexicanas e estrangeiras, inicialmente ligada à mobilidade dos estudantes, reduziu essa mobilidade de geração em geração. Eles também observam que os caminhos de formação mudaram, criando novas relações institucionais assim como novos canais de mobilidade e rompendo com algumas heranças.

As transformações do espaço são também um resultado da mobilidade das pessoas, percebem Miret e Córdoba, que buscam entender como as experiências urbanas no país de acolhimento afetam as mudanças nas formas de habitat no país de origem. Elees se apoiam na experiências biográficas e nos discursos de vinte colombianos, estudantes e migrantes qualificados, que chegaram em Barcelona na década de 2000. Esses migrantes, de volta na Colômbia, adotam novos estilos de vida urbanos, semelhantes aos que conheceram no exterior. Por outro lado, Miret e Cordoba fazem a suposição de que a representação negativa do espaço local urbano, na Colômbia, assim como a representação valorizada e mítica do espaço urbano europeu, podem ter levado vários colombianos a migrarem.

A diversificação e a complexidade das trajetórias migratórias afeta também o curso e a instalação em novos destinos, como o estudou Baby-Collin, focando-se numa migração pouco conhecida, a dos bolivianos nos Estados Unidos, e interrogando-se sobre a experiência dos migrantes.

Finalmente, como o analisam Esses et al. no caso do Canadá, a construção das percepções dos migrantes também é moldada pela cobertura das mídias sobre as "crises" migratórias que integram todos os países num sistema global de mobilidade. Os países da América Central também se incorporam neste sistema, e isto é o tema do artigo de Morales que descreve a sua americanização progressiva após as revoluções da segunda metade do século XX, e sua integração na globalização econômica, ideológica e política através de seus migrantes. Na verdade, os migrantes são atores distantes em suas sociedades de origem, excluídos, ou, pelo menos, mantidos longe dos sistemas sociais, políticos e econômicos. Porém, também são os fornecedores de riquezas, mandam ordens de pagamento enviadas para seus parentes, e isto produz uma reestruturação social e territorial na região. Assim Morales conclui esta matéria apontando para uma rede entre a experiência individual de migração, a mobilidade regional, nacional e internacional, e a globalização. Para ele, o "indivíduo migrante" é um elemento-chave nas mudanças políticas, econômicas e sociais da América Central, como o é para todos os autores dos artigos deste dossiê.

Partir da experiência dos migrantes e dar conta de suas trajetórias, das redes, identidades e dos pertencimentos nos permite desenhar um outro retrato das Américas, um continente onde a mobilidade estrutura profundamente as sociedades e as relações, os indivíduos, as famílias, os grupos, as regiões e os países. 


\section{NOTAS}

1. Aristide R. Zolberg, A Nation by Design. Immigration Policy in the Fashioning of America, Russel Sage Foundation Books at Harvard University Press, 2008.

2. Décimo colóquio anual do Instituto das Américas, organizado por uma equipe de pesquisadores da Universidade Paris Diderot, https://sites.google.com/site/colloqueida2012/

\section{AUTORES}

\section{FRANÇOISE LESTAGE}

Françoise Lestage est professeur des universités en anthropologie et sociologie à l'Université Paris Diderot, UMR URMIS (IRD-CNRS), où elle est co-responsable de l'axe de recherches « Les reconfigurations des migrations contemporaines ». Depuis septembre 2014, elle est détachée au Ministère des Affaires étrangères pour diriger le Centre d'études mexicaines et centraméricaines (CEMCA), Unité mixte CNRS des instituts français à l'étranger (UMIFRE 16) basée à Mexico. Elle est l'auteur de 3 livres en nom propre (1999, 2008, 2011), 2 livres comme coéditrice au Mexique (2011) et en France (2014), 4 directions de dossiers dans revues classées AERES (2009, 2012, 2013, 2014), 51 articles et chapitres de livres. Ces publications ont porté sur les politiques migratoires au Mexique depuis la fin des années 1990 ; sur les relations inter-ethniques en milieu migrant, sur les défunts dans la vie sociale et familiale des migrants; et sur le lien familial et le cycle de vie. Ses recherches actuelles se développent selon trois axes : la gestion publique des états d'affliction des migrants par l'Etat mexicain ; les pratiques et perceptions des « retours » des migrants au Mexique et en Amérique centrale ; les inégalités dans l'accès à la reproduction au Mexique et les circuits de maternité pour autrui. Elle a été membre du conseil scientifique de l'Institut des Amériques, et elle est, ou a été, membre des comités de rédaction des revues Problèmes d'Amérique Latine, Migraciones internacionales, Journal de la Société des Américanistes et Mexican Studies/Estudios Mexicanos.

\section{PAUL SCHOR}

Paul Schor est maître de conférences en histoire et civilisation américaines à l'Université Paris Diderot, UMR LARCA 8225, où il est responsable de l'axe de recherches « Histoire du politique dans le monde anglophone ». Il est l'auteur de Compter et classer. Histoire des catégories de la population dans le recensement américain, 1790-1940, Éditions de l'EHESS, 2009, ouvrage récompensé par le Willi Paul Adams Award de l'Organization of American Historians, 2011 (traduction en langue anglaise sous presse à Oxford University Press, prévue courant 2016) et avec Nicolas Barreyre, De l'émancipation à la ségrégation : le Sud des États-Unis après la guerre de Sécession, 1865-1896, PUF, 2009.Il a publié de nombreux articles et chapitre d'ouvrages sur l'histoire des catégories raciales aux États-Unis, sur l'histoire de l'immigration aux États-Unis et sur l'histoire des États-Unis écrite en Europe, notamment Manfred Berg, Isabel Soto et Paul Schor, "The Weight of Words: writing about race in the United States and Europe", The American Historical Review, 119 (3), June 2014, p. 800-808. Ses recherches actuelles portent sur le rôle des experts et 
travailleurs sociaux dans l'imposition de nouvelles normes de vie quotidienne aux États-Unis au début du vingtième siècle. Il a été membre du conseil scientifique de l'Institut des Amériques et est membre des comités de rédaction des revues Sociétés contemporaines et Transatlantica. 